\title{
Tuning into others' voices: radical listening, learning from difference, and escaping oppression
}

\author{
Kenneth Tobin
}

Received: 22 May 2009/Accepted: 22 May 2009/Published online: 6 June 2009

(C) Springer Science+Business Media B.V. 2009

Over my 35 years of being a teacher, professor, speaker, cultural worker, and researcher, I've been asked many times: "where did you come up with the perspective on schools or media that you used in your article or speech-I've never heard such a point of view before?" Oftentimes my answer involves telling the inquisitor that I simply listened to people who had been deemed failures by the larger society or by the schools they attended. Such individuals, I have learned over the years, often possess some of the most compelling insights into what is actually happening, into how people are seriously harmed by institutions ostensibly constructed to help them improve their lives. Such an emphasis on the power of difference, on gaining new perspectives from individuals who come from a different locale in the social web of reality is central to my purpose here. This power of difference_or as Paulo Freire (1997) articulated it, "a viable novelty"-is key to an ever-expanding sense of criticality. This evolving criticality is dedicated to a neverending search for new ways of seeing, for new social and cultural experiences that provide novel concepts that we can use to better understand the world in a progressive way. (Kincheloe 2008, p. viii)

Joe Kincheloe's greatest attribute is that he lived his life in ways that cohered with the critical edge that he brought to his writing. For example, Joe wrote about the salience of radical listening, which is to understand others' texts in terms of their standpoints and axiological commitments. Joe is one of few people I know who could listen to what a speaker was saying without projecting his own ideas and identity into the conversation. He was rare in hearing the kernel of an idea, and encouraging the speaker to grow that idea in his or her own way. When Joe spoke he not only addressed what others had said, but showed an understanding of its value. That is, his talk contained evidence that he understood what had been said, its associated standpoints, and its potential. Rarely, if ever,

K. Tobin $(\bowtie)$

Urban Education, The Graduate Center of the City University of New York, 365 5th Avenue,

New York, NY 10016-4309, USA

e-mail: ktobin@gc.cuny.edu 
did Joe begin with a statement that reiterated his personal standpoint. Dialogue began with a serious endeavor to explicate others' good ideas. Usually, conversations with Joe were focused, highly interactive and intense, and laced with laughter, humor, and wit. Inevitably they were lengthy as contributors to the dialogue worked together to produce outcomes that reflected the collective as well as individual goals and successes.

Joe was one of the most emotional people I knew. He demonstrated passion concerning issues of equity and injustice and stepped forward to represent the oppressed. Joe experienced social life in very different ways than I did and his stories about experiences we "shared" reflected his multilogicality and capacity to tune into the emotional structures of fields. Being with Joe was a constant reminder that epistemology, ontology and axiology were always salient - on the front burner.

\section{Moving on ...}

Never was the compression of space and time so evident as when Joe Kincheloe passed away in Jamaica in late December of 2008. Within hours of his passing I was informed of his death in an email message, which simultaneously broke the news to a large community of colleagues. The spread of this tragic news was viral. Interestingly, the same technology that transmitted the news of Joe's premature death to scholars around the world now affords ready access to his scholarly products through a plethora of websites and electronic resources, such as Joe's interview of Henry Giroux on YouTube (e.g., http://www. youtube.com/watch?v=UvCs6XkT3-o). A Google search to locate Joe's works provides an overwhelming yield - testimony to the fact that he was a prolific scholar who produced many resources that will continue to shape education globally for many years to come.

As far as Cultural Studies of Science Education (CSSE) is concerned, Joe was a trusted colleague who encouraged the co-editors to proceed with the project to create CSSE as a needed alternative to the status quo. Until now Joe's only publication in CSSE was in the first issue of Volume 1, as principal author in a Forum on sense of place.

With Joe's passing several of the editorial board recommended that we publish The much exaggerated death of positivism in CSSE, as a testimonial to Joe's scholarship and intellectual spirit. In their view, and mine, the article has much for science educators to contemplate and its forthright stance raises questions that can be addressed by scholars in our field. So much of what is done in research is habitual, emphasizing tenets of positivism, a potentially dangerous situation, especially when those tenets align with implicit and explicit stipulations in the guidelines of funding agencies, journals, Institutional Review Boards, and dissertation committees, just to name a few. In the scholarly tradition to which Joe ascribed, Peter Taylor and an international cast of scholars critique the paper in a Forum that raises issues for our ongoing deliberation. Finally, Gillian Bayne, a former student and colleague of Joe's, authors the final article in the first set of papers, a distinguished contributors piece that examines some of Joe's key works in cultural studies and, tangentially, their impact in science education.

\section{Capitalizing on difference}

At a recent meeting of the American Educational Research Association (AERA), held in San Diego, I participated in a session that was oriented towards Gloria Ladson-Billings' culturally responsive teaching (Ladson-Billings 1994). The paper I presented with 
Reynaldo Llena, a teacher researcher, addressed culturally adaptive teaching, arguing that teaching and learning are dialectically related and that successful interactions involve the continuous reproduction and transformation of culture as participants act for the other, expanding their agency and coproducing forms of culture that are oriented toward the collective motives for the activity (Tobin and Llena 2009). Because our research seeks to understand cultural enactment we have adopted (and adapted) a definition of culture that views it as enacted in fields that are structured. One of the designated discussant/critics for the session at AERA, which included numerous papers, called for common definitions for terms such as culture. Numerous publications have addressed the many meanings of culture including William Sewell (1999), whose work provides a foundation for much of our scholarship. However, does the use of a plethora of understandings of culture warrant a call for one clear definition?

How can colleagues understand one another without some effort to produce shared understanding of the social constructs used in scholarly dialogues? A call for definition seems like common sense. However, whether such dialogues would include definitions might be contingent on the particulars of the scholarship. As scholars we must interrogate commonsense to identify hegemons that saturate sensibilities. I regard intersubjectivity as collective and continuous and the schemas that best define social constructs do not float free of the material circumstances of social life. That is, the nuances of all social theory are contingent on structures. David Harvey put it elegantly, "The positivist approach to theory is a problem. Theory should be understood instead as an evolving structure of argument sensitive to encounters with complex ways in which social processes are materially embedded in the web of life" (Harvey 2006, pp. 78-79).

I view it as a necessity to be as clear as possible by surrounding social constructs with examples to clarify the intended range of meanings for salient social constructs. Others who access and appropriate my work are joining a dialogue in which they can contribute, first through radical listening in which they seek to learn as much as possible from the ongoing dialogue in its historical constitution and then contribute their texts, illustrating their appropriations in rich detail, showing how theory reproduces and transforms simultaneously, and above all, how theory is always connected to the salient structures of a study. With this in mind, my standpoint on definitions is that they can comprise thick descriptions and be contingent on the circumstances of a study. At a time when I was struggling to define action I was advised by Heinrich Bauersfeld, "Don't be too concerned with defining action, describe its meaning in use-surround your use with thick descriptions from which the meaning can become apparent." Cognizance of what has come before the definitions will be viable in the context of the activity that is the research. The expectation I have is that, as culture, definitions of social constructs, including definitions of culture, would have thin coherence and associated contradictions, attributable to different structures for the field of the research and language always under-representing social experience (Britzman 1998).

By way of concluding this section I want to return to an issue that is closely related to the call for definition of social constructs like culture, namely, citing the work of others. CSSE has a policy of citing substantively, which is for an author to take something from published work and weave it into the ongoing thesis he or she is developing. In making the decision to cite an excerpt from a published article an author must make every attempt to establish what the excerpt means in the larger context in which it is published. The process of figuring out the meaning is not unlike radical listening. Once the effort is made the meaning of the text will necessarily change because of the structures in the text in which it is to be inserted. Salient is the idea that in their appropriation ideas are transformed, but not 
without an awareness of the meanings that are historically constituted. Readers would not expect the meanings to be identical and in any event, what a scholar takes away from a reading always is a transaction between the scholar and the text, never a question of the meaning being only what an author intended. In our use of published literature, including critique, we ought not privilege our own understandings above others' understandings and in any event, from my polysemic perspective, there always will be numerous meanings of text, nuanced by the motives of the salient activities in which the scholar/reader is a participant. My personal standpoint is to reject the idea that there is one right meaning for a given text. This puts me at odds with those who are apt to prescribe as authoritative and correct their understandings of scholarly works that are foundational to our field. The stance that one set of meanings is correct and others are incorrect can overlook the salience of the purposes readers have in accessing particular works. These purposes structure meaning making and highlight the value of readers being radical listeners as they appropriate others' works.

\section{Constituents of this issue of CSSE}

This issue of CSSE consists of five sets of articles, the first associated with the Kincheloe and Tobin article described above. The four other sets of articles are described in the sub sections that follow.

Identity, elementary science and high stakes testing

Bhaskar Upadhyay addressed the important issue of science teacher identity for an elementary teacher who felt the weight of teaching science in a context in which high stakes tests were an accepted practice in her school and beyond. The paper and the associated Forum delve into issues of how best to research the important construct of identity and, in so doing, numerous methodological issues are addressed, including different ways in which identity can be theorized and researched. The participants in the Forum agree on the importance of including the teacher's voice in classroom research and involving teachers as co-researchers and co-authors. The Forum, which includes authors from Australia, Brazil and the USA also addresses uses of narrative in research on teaching and learning.

One issue raised by Stephen Ritchie in the Forum concerned a large international study undertaken by the Organization for Economic Co-operation and Development (OECD). The OECD Programme for International Student Assessment (PISA) examined science attainment in 59 countries (OECD 2007) in a study focused on scientific literacy, exploring the extent to which students near the end of compulsory education (i.e., 15 year olds) could apply knowledge and skills regarded as essential for full participation in civic life. The implications of the study that I hear most about are that students in the US ranked 29th out of 57 participating countries and more than $24 \%$ of the students tested from the US obtained less than minimal levels of scientific literacy. In other words, the study was an international comparison of science performance that aligned with the neoliberal agenda that supports high stakes testing in the United States. Whereas the teacher in Upadhyay's study felt that the curriculum was constrained by high stakes tests required in Texas, the PISA studies create a climate for arguing that the focus should be on a different type of high stakes test-albeit with goals that seem like a step in the right direction. I offer a cautionary note, citing Harvey (2005), who urges researchers in the social sciences to interpret what they learn from their studies of institutions like schools in a context of 
macrostructures such as neoliberalism that saturate social life and the common sense that supports what we do. Focusing enacted science curricula on high stakes tests seems highly regressive and has the potential to strip away those parts of science that are not tested or are not easily tested. Science educators might explore ways to remove the competition, especially international comparisons, examine ways to foster the collective aspects of knowing and learning science, and identify ways to enact science curricula that afford social transformation and improved life on earth not just for humans, but for all species.

Aboriginal knowledge, power, and the nature of science

Michiel van Eijck and Wolff-Michael Roth provide a feature article that opens up a dialogue on ways in which underrepresented groups might be enticed into science. The article focuses on an Aboriginal student and his life trajectory, which includes an investigation of his practices in science and those used in everyday life. Inevitably the question of what counts as science arises, as do ways to address identities associated with being an Aboriginal and participation in myriad activities, including Western Modern Science (WMS). Alison Sammel and Pauline Chinn take up these issues in a Forum that raises issues of power, Whiteness, White privilege and the role of science education in affording learners identifying and resisting the oppression of social life. Among the issues addressed in this collection of papers are: the crisis of representation that places limits on learning from experience and expressing what we learn textually, the necessity to problematize the ontological and epistemological foundations for science education, relationships between personal and collective agency, and the insufficiency of a science education built upon assumptions of the supremacy of WMS. The papers in this set continue a dialogue that the authors join and contribute to, clearly leaving many issues that warrant further exploration in CSSE and elsewhere. Paramount among the issues placed on the table for further work are, how to theorize and research culture. As I explain above, I do not regard science education as being well served by just one theory of culture and I call for acceptance of difference and use of a bricolage of theories in forthcoming scholarship. However, it is incumbent on authors who situate their work in cultural studies to explicate their standpoints on culture so that, to the extent possible, we do not talk past one another.

Sociocultural perspectives on sustainable development

Laurence and Jean Simonneaux examine sociocultural issues associated with sustainable development. Two of the issues they address are situated locally, in France-the reintroduction of bears in the Pyrenees and wolves in the Mercantour National Park. A third issue, global warming, affords the authors investigating the possibilities for transfer of reasoning patterns across local and global contexts. As in other contributions to this issue of CSSE, the papers in this set adopt different theoretical standpoints and in so doing raise interesting issues for continuing the dialogue about identities and social representations.

The Forum is enriched by the participation of Ramón López-Facal and María Pilar Jiménez-Aleixandre, scholars from Spain, who address issues of personal and national identities and relationships between self and other, conscious and unconscious. Troy Sadler, from the United States, also contributes to the Forum in an analysis of how the authors of the feature article use the socioscientific reasoning framework that he and his colleagues developed some years earlier. Attention is drawn to the way in which Sadler's earlier work is appropriated and the ways the authors explain and justify their standpoints. Of particular interest to me are the logics that underpin the use of others' work and the 
critiques that arise in this set of papers. I wonder, to what extent has and can radical listening inform this dialogue? Have the authors endeavored to understand the position of others by adopting their standpoints? In moving beyond Sadler's earlier articulation of socioscientific reasoning, have Simonneaux and Simonneaux nuanced social theory in the ways Harvey argues social theory always must be nuanced? Or have they simply entered a deadend? As van Eijck and Roth challenged us to think of culture in terms of theories of difference, can we think similarly (i.e., in ways that embrace different) about standpoints, the ontological status of what others have published, and the extent to which we as a community of science educators can and do embrace polysemia?

The paper set raises axiology and its centrality in making sense of issues such as those involved in sustainable development. This is an area in which much more work can be done, extending beyond values to include emotions. Similarly, in pointing out the salience of politics, the issue of macrostructures, especially the ideologies that saturate commonsense notions of being in the world should, to an increasing extent, work their way into the papers published in CSSE. The implications are profound for sociocultural issues such as those raised by Simonneaux and Simonneaux.

Critical pedagogy and research on the teaching and learning science

Jennifer Goldberg and Kate Muir Welsh adopt a Freirean approach in an ethnography in which most of the participants were Latina/o. In the two studies presented in the paper the students were from grade 6 and 3, respectively. Issues that arise in the research include critical pedagogy, conscientization, social justice, the teacher as co-inquirer, and ways in which interviews and videotape can be used as data resources in research. Since I have cited Harvey throughout this editorial I note here that social justice is not theorized explicitly in the paper. Instead there is an assumption that the reader will nod in agreement and the level of intersubjective agreement between the authors and readers is high. That is, social justice points to equity, which assumes freedom to participate in social life. However, the assumptions about freedom being understood similarly across social categories of readers of CSSE and especially the participants in the Forum likely do not hold. Among the questions to be asked are: "Freedom from what?" and "Freedom to do what?" Harvey points out that neoliberalism, that is a pervasive global hegemony, only assumes that participants in social life are free to compete in a free market (Harvey 2005). Just what freedoms are possible in the classes studied by Goldberg and Muir Welsh and what freedoms do the different stakeholders seek? Some of these issues are raised in the Forum and others can be pursued in subsequent publications in CSSE.

Alejandro Gallard emphasizes the importance of classroom research taking account of macrostructures, including political structures associated with race, ethnicity, native language, immigration status, poverty, and religion. He uses personal narratives of his own childhood as an immigrant to the USA and as a non-native speaker of English to highlight hegemony, neocolonialism and a necessity for youth to engage in conscientization. In his examples he makes it clear that assumptions about immigrants often are wide of the mark and cites as examples the hard work they do to raise money to support extended families in their native countries. He deals with several aspects of identity including personal and collective agency and the common situation in which others inscribe identities of Latino/a youth, often according to stereotypes that incorporate deficit perspectives and have longterm deleterious effects. Finally, Gallard looks beyond dualisms and argues for dialectical frameworks in which social constructs, such as race and ethnicity, are theorized as dialectical. There is a bottom line to his work and that is that research that has a critical 
pedagogy as a foundation should search for the connection between lived experiences of participants and hegemonic macrostructures. As is clear from the initial quote that begins this editorial, including the voices of the children and their parents and relatives as well as their teachers and school leaders can enrich studies of the type undertaken by Goldberg and Muir Welsh.

Gale Seiler and Anjali Abraham requested permission to analyze some tapes from the database used by Goldberg and Muir Welsh. Their purpose in so doing was to show how complementary insights could be obtained through different approaches. Their Forum response begins with an analysis of macrostructures, and examines some geo-political structures that mediate social life. The authors proceed with an argument for participatory forms of research to bring polyphonia and polysemia to research on teaching and learning. Considering their suggestion that student conscientization is important prompts me to note that so much is contributed from the collective perspectives emerging from studies in which teachers and students collaborate as co-researchers-now typical in the growing volume of research on the uses of cogenerative dialogue in classroom research (e.g., Tobin and Llena 2009).

\section{References}

Britzman, D. P. (1998). Lost subjects, contested objects. Towards a psychoanalytic inquiry of learning. Albany: State University of New York Press.

Freire, P. (1997). Pedagogy of the heart. New York: Continuum.

Harvey, D. (2005). A brief history of neoliberalism. Oxford, UK: Oxford University Press.

Harvey, D. (2006). Spaces of global capitalism: Toward a theory of uneven geographical development. London: Verso.

Kincheloe, J. L. (2008). Knowledge and critical pedagogy: An introduction. Dordrecht: Springer.

Kincheloe, J. L., McKinley, E., Lim, M., \& Calabrese Barton, A. (2006). Forum: A conversation on 'sense of place' in science learning. Cultural Studies of Science Education, 1, 143-160.

Ladson-Billings, G. (1994). The Dreamkeepers: Successful teaching for African-American students. San Francisco: Jossey-Bass.

OECD. (2007). PISA 2006: Science competencies for tomorrow's world (Volume 1-Analysis). Paris: OECD.

Sewell, W. H. (1999). The concept(s) of culture. In V. E. Bonell \& L. Hunt (Eds.), Beyond the cultural turn (pp. 35-61). Berkeley: University of California Press.

Tobin, K., \& Llena, R. (2009). Producing and maintaining culturally adaptive teaching and learning of science in urban schools. In C. Murphy \& K. Scantlebury (Eds.), Moving forward and broadening perspectives: Coteaching in international contexts. Dordrecht: Springer. 